DOI: 10.20472/IAC.2018.935.055

LEI ZHANG

University of Regina, Canada

\title{
ARTIFICIAL NEURAL NETWORK BASED CHAOTIC GENERATOR DESIGN FOR THE PREDICTION OF FINANCIAL TIME SERIES
}

\begin{abstract}
:
series. The ANN architecture is usually designed and optimized based on trial and error using a given training data set. It is generally required to obtain big data for ANN training in order to achieve good training performance. Financial time series are subject to highly complex conditions of external inputs and their dynamic features can change fast and unpredictably. The aim of this research is to design an adaptive ANN architecture, which can be trained in real time with short time series for near future prediction. ANN based chaotic system generator is designed for the simulation and analysis of the dynamic features in financial time series.
\end{abstract}

\section{Keywords:}

Aritificial Neural Network (ANN), chaotic generator, financial time series, prediction, optimizaiton

JEL Classification: C45, C52, C61 